Arq. Bras. Med. Vet. Zootec., v.69, n.1, p.155-164, 2017

\title{
Produção de novilhos castrados ou não castrados terminados em confinamento em idade jovem ou superjovem
}

\author{
[Production of steers or bulls finished in feedlot at a young age or young steers] \\ J.R. Cullmann ${ }^{1}$, F. Kuss ${ }^{2}$, J.L. Moletta ${ }^{3}$, J.A.C. Lançanova ${ }^{3}$, M.F. Silveira ${ }^{2}$, L.F.G. Menezes ${ }^{2}$, \\ I.C.F. Moura ${ }^{4}$, M. Strack ${ }^{5}$ \\ ${ }^{1}$ Aluno de pós-graduação - Universidade Tecnológica Federal do Paraná - Dois Vizinhos, PR \\ ${ }^{2}$ Universidade Tecnológica Federal do Paraná - Dois Vizinhos, PR \\ ${ }^{3}$ Instituto Agronômico do Paraná - Iapar, PR \\ ${ }^{4}$ Aluno de pós-graduação - Universidade Federal do Paraná - Curitiba, PR \\ ${ }^{5}$ Fundação ABC - Pesquisa e Desenvolvimento Agropecuário - Castro, PR
}

\begin{abstract}
RESUMO
Avaliaram-se o desempenho produtivo e o rendimento de cortes comercias da carcaça de animais castrados ou não castrados terminados em confinamento e abatidos em idade jovem ou superjovem, alimentados com uma dieta contendo $11,2 \%$ de proteína bruta e 3,07Mcal de energia digestível $/ \mathrm{kg}$ de matéria seca, composta de $50 \%$ de volumoso e $50 \%$ de concentrado. A idade no início do confinamento dos animais superjovens e jovens foi de nove e 22 meses, respectivamente. Maior PF foi observado para os animais jovens não castrados. O GMD foi 31\% superior em favor dos novilhos jovens em relação aos superjovens. O CMS foi $27 \%$ superior para os novilhos jovens sobre os superjovens, e os novilhos não castrados consumiram 9\% mais $\mathrm{kg}$ de matéria seca quando comparados aos castrados. A diferença de peso da meia carcaça entre animais não castrados e castrados foi de $43 \%$ para os jovens e de $18 \%$ para os superjovens. Maior percentual do corte serrote foi observado nos novilhos jovens castrados. Novilhos jovens apresentaram maior ganho de peso médio diário, bem como novilhos jovens não castrados apresentaram maior peso final. Animais não castrados apresentaram maiores pesos de meia carcaça fria, percentual de dianteiro e porção comestível do dianteiro em relação aos castrados.
\end{abstract}

Palavras-chave: Canchim, conversão alimentar, cortes comerciais, ganho de peso, Purunã

\begin{abstract}
The productive performance and yield of commercial cuts of the carcass of non-castrate or castrated males feedlot finished and slaughtered at a young age or young steers, fed a diet containing 11.2\% crude protein and $3.07 \mathrm{Mcal}$ of digestible energy / $\mathrm{kg}$ of dry matter, composed of 50\% roughage and 50\% concentrate were evaluated. The initial age at the beginning of confinement of young steers and steers were 9 and 22 months, respectively. Greater FW was observed for young non-castrate. The ADG was $31 \%$ higher for the steers in relation to young steers. The DMI was $27 \%$ higher for steers than young steers and non-castrated consumed 9\% more dry matter $\mathrm{kg}$ compared to the castrated. The half-carcass weight difference between non-castrated and castrated animals was 43\% for steers and 18\% for young steers. Higher percentage hacksaw cut was observed in castrated steers. Steers showed higher average daily weight gain, as well as non-castrate steers showed higher final weight. Non-castrate animals have higher half cold carcass weights, front percentage, and of edible portion of the front in relation to castrated.
\end{abstract}

Keywords: Canchim, commercial cuts, feed conversion, Purunã, weight gain

Recebido em 14 de julho de 2016

Aceito em 20 de julho de 2016

E-mail: jrcullmann@gmail.com

Apoio financeiro: CNPq (Projeto Universal 485012/2012-4) e do Instituto Agronômico do Paraná 


\section{INTRODUÇÃO}

No agronegócio brasileiro, a pecuária de corte apresenta-se como uma das mais importantes atividades. No ano de 2013, o rebanho bovino brasileiro era superior a 211 milhões de cabeças (Food..., 2015). Em 2014, foram abatidos no Brasil 42,07 milhões de cabeças, produzindo cerca de 10,07 milhões de toneladas de carne bovina, sendo $11 \%$ dos abates de bovinos provenientes de confinamentos. Detentor do maior rebanho comercial do mundo, o Brasil lidera as exportações mundiais de carne. Em 2014, exportou 2,09 milhões de toneladas em equivalente carcaça. A pecuária de corte representa aproximadamente $12 \%$ do produto interno bruto do agronegócio nacional (Anuário..., 2015).

Para o Brasil permanecer nessa posição de destaque, conquistar novos mercados e melhorar a produtividade do sistema, algumas tecnologias são necessárias, como a utilização do confinamento, fundamental para o abate de animais na entressafra, buscando obter melhores preços (Coutinho Filho et al., 2006).

A redução da idade de abate para 14-16 meses surge como uma alternativa, pois pode proporcionar maior giro de capital investido, liberar áreas na propriedade de ciclo completo, aumentar o número de matrizes e resultar em maior produção de bezerros (Missio et al., 2009). A produção de bovinos superjovens em confinamento explora a eficiência biológica, conciliando os efeitos de manipulação de fatores genéticos e ambientais nas transformações dos tecidos durante a fase acelerada do crescimento (Rubiano et al., 2009). Pacheco et al. (2005a) observaram melhor conversão alimentar em favor dos animais superjovens, em decorrência do menor ímpeto de deposição de gordura na fase inicial de alimentação dos superjovens, priorizando o crescimento muscular, que é um processo que exige menos energia por $\mathrm{kg}$ de incremento.

Outra alternativa é a utilização de machos não castrados para a produção de carne (Restle et al., 2000), que resulta em maior peso de abate (Moletta et al., 2014), devido ao efeito anabolizante do hormônio testosterona
(Seideman et al., 1982). De acordo com Silva et al. (2012), animais não castrados apresentam maior ganho de peso e eficiência de utilização dos alimentos.

No entanto, o efeito da interação entre categorias e condições sexuais é pouco conhecido. Assim, objetivou-se avaliar o desempenho produtivo e o rendimento de cortes comercias da carcaça de novilhos castrados ou não castrados para abate em idade jovem ou superjovem, terminados em confinamento.

\section{MATERIAL E MÉTODOS}

O experimento foi conduzido na Estação Experimental Fazenda Modelo do Instituto Agronômico do Paraná - FM/Iapar, situada no município de Ponta Grossa, região centro-sul do estado. Foram utilizados 32 animais não castrados ou castrados do grupo genético $1 / 2$ Purunã (igual proporção de sangue Angus, Charolês, Caracu e Canchim) $+1 / 2$ Canchim, distribuídos segundo a idade de abate, em dois sistemas de terminação, jovem (26 meses) e superjovem (16 meses).

O experimento foi conduzido em confinamento coberto, onde os animais permaneceram em baias individuais, providas de cocho de madeira e bebedouros de alvenaria. Os animais foram alimentados com uma dieta contendo $11,2 \%$ de proteína bruta e 3,07Mcal de energia digestível/kg de matéria seca (MS), composta de $50 \%$ de volumoso (silagem de milho) e $50 \%$ de concentrado contendo $73,0 \%$ de milho grão, $25 \%$ de farelo de soja, $1 \%$ de sal comum e $1 \%$ de calcário calcítico, com base na MS.

A alimentação foi fornecida em duas refeições, pela manhã e à tarde, sendo a silagem e o concentrado fornecidos separadamente no cocho. $\mathrm{Na}$ manhã do dia seguinte, antes da primeira alimentação, eram retiradas e pesadas as sobras de alimento para cálculo do consumo de matéria seca dos animais e ajuste da quantidade oferecida, uma vez que as sobras da silagem foram mantidas ao redor de $10 \%$ do total oferecido. Foram coletadas amostras da silagem e do concentrado a cada 21 dias para a realização das análises bromatológicas, sendo os resultados apresentados na Tab. 1. 
Tabela 1. Teores de matéria seca (MS), proteína bruta, fibra em detergente neutro, fibra em detergente ácido, extrato etéreo, matéria mineral, extrativos não nitrogenados, matéria orgânica, nutrientes digestíveis totais, energia digestível

\begin{tabular}{lccc} 
& \multicolumn{3}{c}{ Alimento } \\
\cline { 2 - 4 } Parâmetros & Silagem de milho & Milho em grão & Farelo de soja \\
\hline Matéria seca (MS), \% & 35,84 & 89,37 & 89,54 \\
Proteína bruta, \% MS & 5,66 & 7,67 & 44,75 \\
Fibra em detergente neutro, \% MS & 43,55 & 21,88 & 12,97 \\
Fibra em detergente ácido, \% & 26,84 & 13,08 & 4,40 \\
Extrato etéreo, \% MS & 2,19 & 4,80 & 2,37 \\
Matéria mineral, \% MS & 3,06 & 1,24 & 5,98 \\
Extrativo não nitrogenado, \% MS & 67,68 & 75,83 & 43,38 \\
Matéria orgânica, \% MS & 96,90 & 98,76 & 94,02 \\
Nutrientes digestíveis totais, \% & 60,48 & 81,65 & 69,75 \\
Energia digestível $^{1}$, Mcal/kg MS & 2,67 & 3,60 & 3,07 \\
\hline
\end{tabular}

Dados obtidos no Laboratório de Análises de Alimentos - Iapar.

${ }^{1} \mathrm{ED}=4,409 * \mathrm{NDT} / 100$.

Antecedendo o período de adaptação experimental, os animais da categoria jovem foram desmamados e mantidos em pastagem de Hemarthria altíssima cv Flórida, nos períodos de primavera-verão e outono-inverno, em pastagem cultivada de aveia azevém, enquanto os animais da categoria superjovem permaneceram em confinamento. Os animais castrados foram submetidos a este procedimento aos sete meses de idade, pelo método cirúrgico de orquiepididectomia bilateral (retirada dos testículos por meio cirúrgico e ligadura do cordão pela cauterização).

A idade inicial no começo do confinamento dos animais superjovens e jovens foi de nove e 22 meses, respectivamente. Duas semanas antes do início do experimento, os animais foram submetidos a um período de adaptação à dieta experimental e ao manejo do confinamento. Foram pesados individualmente, no início e no final do período experimental, e em períodos intermediários de 21 dias, após jejum de sólidos de 16 horas. O final do experimento ocorreu quando a média dos animais de cada grupo atingiu a condição corporal de 3,5 pontos = ligeiramente gordo a 4,0 pontos $=$ gordo, respectivamente, visando ao grau de acabamento preconizado pelos frigoríficos (entre 3 e $6 \mathrm{~mm}$ ).

Quando a média dos lotes atingiu o escore corporal preconizado, os animais foram submetidos a jejum de sólido de 16 horas, pesados e transportados em caminhão boiadeiro até o frigorífico comercial, onde foram abatidos após o descanso mínimo de 24 horas, conforme fluxo de abate normal do estabelecimento, permanecendo mais 24 horas em câmara fria.

Após o resfriamento da carcaça, a meia carcaça esquerda foi pesada e posteriormente separada nos cortes primários: corte serrote, que corresponde à região posterior da carcaça separada do dianteiro, entre a quinta e a sexta costelas, e do costilhar, a aproximadamente $20 \mathrm{~cm}$ da coluna vertebral; o dianteiro, que compreende pescoço, paleta, braço e cinco costelas; e o costilhar, que compreende a região da sexta costela mais músculos abdominais. Depois de separados, foram aferidos os pesos absolutos dos cortes para se calcular a porcentagem em relação ao peso de meia carcaça fria.

Os cortes primários foram desossados durante $\mathrm{o}$ mesmo turno pelas mesmas pessoas, visando manter o mesmo corte e padrões de corte, resultando nos respectivos cortes raquete, coração, músculo da paleta, peixinho, pescoço, acém, peito, carne da costela, filé-mignon, picanha, patinho, lagarto, coxão mole, coxão duro, maminha, alcatra, contra filé e retalhas.

O delineamento experimental foi o inteiramente ao acaso, em arranjo fatorial 2 × 2 (idades de abate e condição sexual) com oito repetições por tratamento, totalizando 32 animais, de modo que cada unidade experimental era representada por um animal. 


\section{Cullmann et al.}

O modelo estatístico utilizado foi:

$$
\mathrm{Yijk}=\mu+\mathrm{Ci}+\mathrm{Sj}+\mathrm{CSij}+\mathrm{Eijk}
$$

em que: Yijk = variáveis dependentes; $\mu=$ média de todas as observações; $\mathrm{Ci}=$ efeito da i-ésima categoria animal, em que: $\mathrm{i}=$ jovem ou superjovem; $\mathrm{Sj}=$ efeito da j-ésima condição sexual, em que $\mathrm{j}$ = não castrado ou castrado; $\mathrm{CS} i \mathrm{j}$ $=$ efeito da interação categoria animal $\times$ condição sexual; e Eijk = erro aleatório associado a cada observação.

Os dados foram testados quanto à normalidade, por meio do teste de Shapiro-Wilk, de forma que, quando não apresentavam comportamento normal, foram ajustados por meio da transformação por Box-Cox. Os dados foram submetidos à análise de variância e ao teste $\mathrm{T}$, a $5 \%$ de significância.

\section{RESULTADOS E DISCUSSÃO}

$\mathrm{O}$ peso inicial (PI) e o ganho de peso médio diário (GMD) não apresentaram interação entre categoria $\mathrm{x}$ condição sexual, ao passo que, para peso final (PF) e ganho de peso vivo (GPV), a interação entre os dois fatores foi significativa (Tab. 2). Entre as categorias e condições sexuais, ocorreram diferentes períodos de confinamento, variando de 147 dias para os animais jovens até 243 dias para os superjovens, ambos da condição sexual castrado, ressaltando que o final do período experimental ocorreu quando os animais atingiram a condição corporal de 3,5 a 4,0 pontos, em uma escala de 1 a 5.

Tabela 2. Médias para período de confinamento, peso inicial (PI), peso final (PF), ganho de peso vivo (GPV) e ganho de peso médio diário (GMD), de acordo com a categoria e a condição sexual

\begin{tabular}{|c|c|c|c|}
\hline \multirow{2}{*}{ Categoria } & \multicolumn{2}{|c|}{----- Condição sexual ----- } & \multirow{2}{*}{ Média } \\
\hline & Castrado & Não castrado & \\
\hline \multicolumn{4}{|c|}{ Período de confinamento, dias } \\
\hline Jovem & 147 & 195 & - \\
\hline Superjovem & 243 & 243 & - \\
\hline \multicolumn{4}{|c|}{ PI, kg } \\
\hline Jovem & $268,67 \pm 24,94$ & $307,78 \pm 36,53$ & $288,22 \pm 36,41 \mathrm{~A}$ \\
\hline Superjovem & $199,43 \pm 11,21$ & $225,00 \pm 12,67$ & $212,21 \pm 17,56 \mathrm{~B}$ \\
\hline \multirow{2}{*}{\multicolumn{4}{|c|}{$\begin{array}{l}266,39 \pm 50,51 \mathrm{~A} \\
\mathrm{PF}, \mathrm{kg}\end{array}$}} \\
\hline & & & \\
\hline Jovem & $455,22 \pm 49,63 b$ & $581,11 \pm 59,83 a$ & $518,17 \pm 83,90$ \\
\hline Superjovem & $437,29 \pm 18,09 \mathrm{~b}$ & $478,00 \pm 33,24 b$ & $457,64 \pm 33,69$ \\
\hline Média & $446,25 \pm 39,10$ & $529,56 \pm 71,33$ & \\
\hline \multicolumn{4}{|c|}{$\mathrm{GPV}, \mathrm{kg}$} \\
\hline Jovem & $186,56 \pm 35,96 \mathrm{c}$ & $273,33 \pm 44,49 a$ & $229,94 \pm 59,44$ \\
\hline Superjovem & $237,86 \pm 16,88 b$ & $253,00 \pm 27,91 \mathrm{ab}$ & $245,43 \pm 23,93$ \\
\hline Média & $212,21 \pm 38,66$ & $263,17 \pm 37,94$ & \\
\hline \multicolumn{4}{|c|}{ GMD, kg dia } \\
\hline Jovem & $1,28 \pm 0,24$ & $1,39 \pm 0,24$ & $1,34 \pm 0,24 \mathrm{~A}$ \\
\hline Superjovem & $1,00 \pm 0,06$ & $1,05 \pm 0,12$ & $1,02 \pm 0,10 \mathrm{~B}$ \\
\hline Média & $1,14 \pm 0,23$ & $1,22 \pm 0,26$ & \\
\hline
\end{tabular}

A, B: letras diferentes na coluna ou na linha diferem $(\mathrm{P}<0,05)$ na mesma característica, pelo teste $\mathrm{t}$.

a, b, c: médias seguidas por letras minúsculas diferentes, para mesma característica, diferem $(\mathrm{P}<0,05)$ pelo teste $t$.

O PI foi superior para os animais não castrados em relação aos castrados, decorrente do maior desenvolvimento corporal, bem como para a categoria jovem em relação à superjovem, o que se justifica pela maior idade dos animais jovens. Novilhos jovens não castrados apresentaram maior PF que os superjovens de mesma condição sexual e que os castrados. Essa superioridade em relação aos jovens castrados deve-se ao maior tempo de confinamento e PI, e em relação aos superjovens não castrados é reflexo do maior PI e GMD.

Outro fator que contribuiu para o maior PF dos animais não castrados é a composição de ganho, devido à ação hormonal da testosterona, em que bovinos não castrados produzem mais proteína por unidade de energia digestível do que os 
castrados, resultando na diminuição da deposição precoce de gordura, inclusive a subcutânea, fazendo com que os animais permanecessem mais tempo em confinamento (Vittori et al., 2007). Entretanto, isso não se evidenciou na categoria superjovem, em que os animais não castrados apresentaram peso similar aos animais castrados, atingindo a condição corporal com peso de abate próximo ao desejado pelos frigoríficos, que é de 3 a $6 \mathrm{~mm}$.

O GMD não foi influenciado pela condição sexual, semelhante aos resultados encontrados por Vittori et al. (2007), justificando que dietas com maior teor de proteína poderiam proporcionar maiores GMD aos animais não castrados devido ao efeito da testosterona. Entretanto, tal resultado diferencia-se dos observados por Silva et al. (2012) e Restle et al. (2000), com bovinos terminados aos 15 e 36 meses, respectivamente, ambos em períodos de confinamento de 84 dias e superioridade em favor dos animais não castrados. Os resultados obtidos neste trabalho são inferiores aos observados por Fernandes et al. (2007), em estudo com animais Canchim, castrados ou não castrados (1,30 contra $1,65 \mathrm{~kg} / \mathrm{dia}$, respectivamente) terminados em confinamento, abatidos com aproximadamente 19 meses de idade.

Entre as categorias, verifica-se superioridade no GMD dos animais jovens de 31,4\% em relação aos superjovens, evidenciando a ocorrência de ganho compensatório. Da mesma forma foi descrito em trabalhos realizados por Pacheco et al. (2005a) e Gottschall et al. (2009), que observaram superioridade de 21,1 e $25,9 \%$ em favor dos jovens em relação aos superjovens.

Hersom et al. (2004) comentam que animais que sofreram algum tipo de restrição alimentar prévia tendem a apresentar um ganho ou crescimento compensatório quando passam a receber dietas de melhor qualidade. Sabendo-se que os animais jovens foram mantidos em pastagem e os superjovens em confinamento durante a fase de recria e analisando o peso inicial dos animais, os ganhos de peso médio diário até o início do experimento, possivelmente, não foram superiores a 0,737 e $0,351 \mathrm{~kg}$, respectivamente. Gottschall et al. (2009) descrevem que o crescimento compensatório tende a se manifestar de forma mais intensa em animais com estrutura corporal mais desenvolvida, mas que, em algum momento, sofreram limitação nutricional, mesmo que de baixa intensidade.

Na Tab. 3, são apresentadas as médias referentes ao consumo de matéria seca (CMS) expresso em $\mathrm{kg} / \mathrm{dia}$, em percentual do peso vivo (CMSPV), por unidade de tamanho metabólico (CMSTM), e conversão alimentar (CA), de acordo com a categoria e a condição sexual. O CMS não apresentou interação entre categoria e condição sexual. Entre as categorias, os animais jovens apresentaram maior consumo aos superjovens em 26,7\%. Pacheco et al. (2005a), ao trabalharem com animais $5 / 8$ Charolês $3 / 8$ Nelore e $5 / 8$ Nelore $3 / 8$ Charolês, observaram diferença no CMS para as categorias jovem e superjovem de $43,6 \%$ (9,62 contra $6,70 \mathrm{~kg} / \mathrm{dia}$, respectivamente). Em se tratando da condição sexual, verifica-se superioridade dos não castrados em relação aos castrados para CMS, possivelmente relacionada ao maior PI e PF dos não castrados (Tab. 2). Vittori et al. (2007) comentam que o tamanho do animal é um dos fatores que influenciam o consumo de alimentos, podendo-se esperar maior consumo em animais maiores, devido à maior exigência para manutenção. Moletta et al. (2014), ao trabalharem com novilhos confinados aos 20 meses, não verificaram diferença no CMS para condição sexual. Da mesma forma, Vittori et al. (2007), quando trabalharam com bovinos em idade jovem, não observaram diferença no consumo de matéria seca, apesar de ter sido observada diferença para peso final em favor dos animais não castrados. Assim como Silva et al. (2012), não observaram diferença no CMS, porém os animais não castrados e castrados apresentaram peso final semelhante. 
Tabela 3. Médias para consumo de matéria seca em $\mathrm{kg}$ (CMS), em relação a $100 \mathrm{~kg}$ de peso vivo (CMSPV), em gramas, por unidade de tamanho metabólico (CMSTM), e conversão alimentar (CA), de acordo com a categoria e a condição sexual

\begin{tabular}{|c|c|c|c|}
\hline \multirow{2}{*}{ Categoria } & \multicolumn{2}{|c|}{----- Condição sexual ----- } & \multirow{2}{*}{ Média } \\
\hline & Castrado & Não castrado & \\
\hline \multicolumn{4}{|c|}{ CMS, $\mathrm{kg} \mathrm{dia}^{-1}$} \\
\hline Jovem & $9,37 \pm 1,35$ & $10,20 \pm 0,98$ & $9,78 \pm 1,22 \mathrm{~A}$ \\
\hline Superjovem & $7,38 \pm 0,62$ & $8,06 \pm 0,44$ & $7,72 \pm 0,62 \mathrm{~B}$ \\
\hline Média & $8,37 \pm 1,47 \mathrm{~B}$ & $9,13 \pm 1,33 \mathrm{~A}$ & \\
\hline \multicolumn{4}{|c|}{ CMSPV, $\mathrm{kg}$ MS/100 kg de PV } \\
\hline Jovem & $2,58 \pm 0,24 \mathrm{a}$ & $2,28 \pm 0,09 \mathrm{~b}$ & $2,43 \pm 0,23$ \\
\hline Superjovem & $2,36 \pm 0,18 b$ & $2,34 \pm 0,12 b$ & $2,35 \pm 0,50$ \\
\hline Média & $2,47 \pm 0,24$ & $2,31 \pm 0,10$ & \\
\hline \multicolumn{4}{|c|}{ CMSTM, g de MS/PV ${ }^{0,75}$} \\
\hline Jovem & $112,38 \pm 11,32$ & $104,55 \pm 4,35$ & $108,47 \pm 9,24 \mathrm{~A}$ \\
\hline Superjovem & $98,72 \pm 7,74$ & $100,21 \pm 4,57$ & $99,46 \pm 6,06 \mathrm{~B}$ \\
\hline Média & $105,55 \pm 11,89$ & $102,38 \pm 4,86$ & \\
\hline \multicolumn{4}{|c|}{$\mathrm{CA}, \mathrm{kg} \mathrm{MS} / \mathrm{kg}$ ganho } \\
\hline Jovem & $8,43 \pm 2,08$ & $8,68 \pm 2,55$ & $8,56 \pm 2,26$ \\
\hline Superjovem & $9,04 \pm 1,75$ & $8,62 \pm 0,92$ & $8,83 \pm 1,34$ \\
\hline Média & $8,74 \pm 1,91$ & $8,65 \pm 1,90$ & \\
\hline
\end{tabular}

A, B: letras diferentes na coluna ou na linha diferem $(\mathrm{P}<0,05)$ na mesma característica, pelo teste $\mathrm{t}$.

$\mathrm{a}, \mathrm{b}, \mathrm{c}$ : médias seguidas por letras minúsculas diferentes, para mesma característica, diferem $(\mathrm{P}<0,05)$ pelo teste $\mathrm{t}$.

O CMS, quando ajustado para $100 \mathrm{~kg}$ de peso vivo, apresentou interação significativa entre categoria e condição sexual, em que os animais jovens castrados mostraram-se superiores aos demais. Em se tratando do CMSTM, não foi verificada interação significativa entre categoria e condição sexual, apenas diferença na categoria, com superioridade em favor dos animais jovens sobre os superjovens, semelhante ao trabalho realizado por Pacheco et al. (2005a), sendo observado 108,41 contra 81,94g, respectivamente. A semelhança entre a condição sexual neste trabalho também foi observada por Véras et al. (2008), porém em proporções menores, 75,25 e $69,10 \mathrm{~g}$ de $\mathrm{MS} / \mathrm{PV}^{0,75}$ para machos castrados e não castrados, respectivamente.

Não foi verificado efeito da categoria ou da condição sexual sobre a conversão alimentar (CA). A similaridade observada na condição sexual também foi observada por Vittori et al. (2007), enquanto Marcondes et al. (2008) constataram melhor CA em favor dos animais não castrados. Em se tratando de categoria, diferentemente deste experimento, Prado et al. (2015) e Pinto et al. (2015) verificaram que os animais superjovens foram mais eficientes em converter alimento consumido em ganho de peso em relação aos jovens, porque apresentaram CMS semelhante e maior GMD, diferentemente deste experimento, em que os superjovens apresentaram menor CMS mas também ganharam menos peso que os animais jovens.

Quanto ao peso de meia carcaça fria (Tab. 4), verifica-se interação entre categoria e condição sexual. Para ambas as categorias, jovem e superjovem, os animais não castrados apresentaram peso de meia carcaça superior aos animais castrados em 43 e 18,3\%, respectivamente, reflexo da superioridade dos animais não castrados para $\mathrm{PF}$, embora tenha sido verificada apenas diferença numérica para os superjovens (Tab. 2). Comportamentos similares também foram observados em estudos de Fernandes et al. (2007) e Moletta et al. (2014) em razão do efeito anabolizante dos hormônios andrógenos produzidos por animais não castrados (Seideman et al., 1982).

Ao se analisarem os cortes primários da meia carcaça, observa-se que o dianteiro não apresentou interação significativa entre categoria e condição sexual quando avaliado em peso relativo. Os animais não castrados foram superiores $8 \%$ em relação aos castrados. Isso está relacionado apenas ao aumento na proporção comestível em favor dos não castrados, visto que o peso relativo de osso não diferiu. Maiores proporções do dianteiro em favor dos animais não castrados também são relatados por Freitas et al. (2008) e Marcondes et al. (2008). Além do maior desenvolvimento muscular dos animais 
não castrados, o efeito anabolizante do hormônio testosterona também compromete outras características da carcaça relacionadas ao dimorfismo sexual, como o aumento do rendimento do dianteiro (Seideman et al., 1982). Para o costilhar, observa-se similaridade tanto na categoria como para condição sexual.

O corte serrote apresentou interação significativa entre categoria e condição sexual. Maior proporção do corte serrote foi observada para os animais jovens castrados, seguidos pelos superjovens castrados e a menor proporção do corte serrote foi observada nos animais jovens não castrados. Observa-se que essas diferenças estão relacionadas à porção comestível no corte serrote, visto que a proporção de ossos neste não apresenta diferença. Pacheco et al. (2005b) também observaram a maior proporção do corte serrote em favor dos animais jovens, em trabalho realizado com animais castrados.

Tabela 4. Rendimento dos cortes comerciais de meia carcaça de bovinos terminados em confinamento, de acordo com a categoria e condição sexual

\begin{tabular}{|c|c|c|c|}
\hline \multicolumn{4}{|c|}{----- Condição sexual ----- } \\
\hline Categoria & Castrado & Não castrado & Média \\
\hline \multicolumn{4}{|c|}{----- Meia carcaça, kg ----- } \\
\hline Jovem & $117,31 \pm 8,76 \mathrm{c}$ & $167,81 \pm 22,08 \mathrm{a}$ & $142,56 \pm 30,97$ \\
\hline Superjovem & $120,22 \pm 3,45 \mathrm{c}$ & $142,22 \pm 8,34 \mathrm{~b}$ & $131,22 \pm 13,07$ \\
\hline Média & $118,76 \pm 6,48$ & $155,01 \pm 20,72$ & \\
\hline \multicolumn{4}{|c|}{ Dianteiro, $\%$} \\
\hline Jovem & $37,08 \pm 1,73$ & $40,11 \pm 2,08$ & $38,60 \pm 2,41$ \\
\hline Superjovem & $36,81 \pm 1,61$ & $39,54 \pm 2,72$ & $38,17 \pm 2,55$ \\
\hline Média & $36,94 \pm 1,58 \mathrm{~B}$ & $39,83 \pm 2,30 \mathrm{~A}$ & \\
\hline \multicolumn{4}{|c|}{ Costilhar, $\%$} \\
\hline Jovem & $17,14 \pm 1,72$ & $18,03 \pm 1,31$ & $17,59 \pm 1,52$ \\
\hline Superjovem & $19,58 \pm 1,33$ & $17,70 \pm 3,11$ & $18,64 \pm 2,46$ \\
\hline Média & $18,36 \pm 1,94$ & $17,86 \pm 2,26$ & \\
\hline \multicolumn{4}{|c|}{ Serrote, $\%$} \\
\hline Jovem & $45,78 \pm 0,78 \mathrm{a}$ & $41,86 \pm 1,61 \mathrm{c}$ & $43,82 \pm 2,39$ \\
\hline Superjovem & $43,61 \pm 0,73 b$ & $42,77 \pm 1,41 \mathrm{bc}$ & $43,19 \pm 1,15$ \\
\hline Média & $44,69 \pm 1,94$ & $42,31 \pm 1,50$ & \\
\hline \multicolumn{4}{|c|}{$\begin{array}{c}\text {----- Porção comestível, } \% \text {----- } \\
\text { Dianteiro, } \%\end{array}$} \\
\hline Jovem & $28,40 \pm 1,36$ & $31,17 \pm 2,32$ & $29,78 \pm 2,31$ \\
\hline Superjovem & $27,28 \pm 1,02$ & $30,75 \pm 2,58$ & $29,01 \pm 2,60$ \\
\hline Média & $27,84 \pm 1,28 \mathrm{~B}$ & $30,96 \pm 2,32 \mathrm{~A}$ & \\
\hline \multicolumn{4}{|c|}{ Costilhar, \% } \\
\hline Jovem & $14,65 \pm 1,65$ & $15,35 \pm 1,21$ & $15,00 \pm 1,42$ \\
\hline Superjovem & $17,21 \pm 1,10$ & $15,32 \pm 3,33$ & $16,26 \pm 2,54$ \\
\hline Média & $15,92 \pm 1,89$ & $15,33 \pm 2,36$ & \\
\hline \multicolumn{4}{|c|}{ Serrote, $\%$} \\
\hline Jovem & $38,15 \pm 1,59 a$ & $34,08 \pm 0,82 b$ & $36,12 \pm 2,45$ \\
\hline Superjovem & $34,84 \pm 1,64 b$ & $34,52 \pm 1,35 \mathrm{~b}$ & $34,68 \pm 1,43$ \\
\hline Média & $36,50 \pm 2,32$ & $34,30 \pm 1,08$ & \\
\hline \multicolumn{4}{|c|}{--- Osso, \% ---- } \\
\hline \multicolumn{4}{|c|}{ Dianteiro, $\%$} \\
\hline Jovem & $8,68 \pm 0,61$ & $8,95 \pm 0,83$ & $8,81 \pm 0,70$ \\
\hline Superjovem & $9,52 \pm 0,65$ & $8,79 \pm 0,66$ & $9,16 \pm 0,73$ \\
\hline Média & $9,10 \pm 0,74$ & $8,87 \pm 0,71$ & \\
\hline \multicolumn{4}{|c|}{ Costilhar, \% } \\
\hline Jovem & $2,49 \pm 0,17$ & $2,68 \pm 0,18$ & $2,59 \pm 0,19$ \\
\hline Superjovem & $2,38 \pm 0,38$ & $2,38 \pm 0,35$ & $2,38 \pm 0,34$ \\
\hline Média & $2,44 \pm 0,29$ & $2,53 \pm 0,30$ & \\
\hline \multicolumn{4}{|c|}{ Serrote, $\%$} \\
\hline Jovem & $7,63 \pm 1,28$ & $7,77 \pm 0,86$ & $7,70 \pm 1,03$ \\
\hline Superjovem & $8,77 \pm 1,31$ & $8,25 \pm 2,12$ & $8,51 \pm 1,69$ \\
\hline Média & $8,20 \pm 1,36$ & $8,01 \pm 1,55$ & \\
\hline
\end{tabular}

A, B: letras diferentes na coluna ou na linha diferem $(\mathrm{P}<0,05)$ na mesma característica, pelo teste $\mathrm{t}$.

$\mathrm{a}, \mathrm{b}, \mathrm{c}$ : médias seguidas por letras minúsculas diferentes, para mesma característica, diferem $(\mathrm{P}<0,05)$ pelo teste $\mathrm{t}$. 


\section{Cullmann et al.}

No caso da semelhança observada entre castrados e não castrados na categoria superjovem, esta relacionada à menor idade de abate, não houve tempo necessário para ser observado efeito do dimorfismo sexual e alteração na proporção dos cortes primários, reduzindo a proporção do serrote nos animais não castrados, da mesma forma que observado por Pacheco et al. (2013), quando avaliaram animais superjovens não castrados e castrados.
Os cortes desossados do dianteiro: raquete, peixinho, coração, músculo da paleta e peito apresentaram interação significativa entre categoria e condição sexual (Tab. 5). Os maiores percentuais dos cortes raquete e peito foram observados nos novilhos superjovens não castrados. Para o corte peixinho, animais jovens castrados foram superiores aos demais. Os animais superjovens castrados apresentaram maiores proporções dos cortes coração e músculo.

Tabela 5. Rendimento dos cortes desossados do dianteiro de bovinos terminados em confinamento, de acordo com a categoria e a condição sexual

\begin{tabular}{|c|c|c|c|}
\hline \multicolumn{4}{|c|}{----- Condição sexual ----- } \\
\hline Categoria & Castrado & Não castrado & Média \\
\hline \multicolumn{4}{|c|}{ Raquete, \% } \\
\hline Jovem & $2,75 \pm 0,61 b$ & $2,32 \pm 0,33 \mathrm{bc}$ & $2,54 \pm 0,51$ \\
\hline Superjovem & $1,85 \pm 0,11 \mathrm{c}$ & $3,79 \pm 0,22 \mathrm{a}$ & $2,82 \pm 1,03$ \\
\hline Média & $2,30 \pm 0,63$ & $3,05 \pm 0,82$ & \\
\hline \multicolumn{4}{|c|}{ Peixinho, \% } \\
\hline Jovem & $1,53 \pm 0,10 \mathrm{a}$ & $1,30 \pm 0,18 b$ & $1,41 \pm 0,18$ \\
\hline Superjovem & $1,11 \pm 0,11 \mathrm{c}$ & $1,19 \pm 0,07 \mathrm{c}$ & $1,15 \pm 0,10$ \\
\hline Média & $1,32 \pm 0,24$ & $1,24 \pm 0,14$ & \\
\hline \multicolumn{4}{|c|}{ Coração, \% } \\
\hline Jovem & $4,72 \pm 0,75 b c$ & $5,47 \pm 0,85 a b$ & $5,09 \pm 0,85$ \\
\hline Superjovem & $5,92 \pm 0,38 \mathrm{a}$ & $4,24 \pm 0,43 \mathrm{c}$ & $5,09 \pm 0,97$ \\
\hline Média & $5,32 \pm 0,85$ & $4,86 \pm 0,90$ & \\
\hline \multicolumn{4}{|c|}{ Músculo, \% } \\
\hline Jovem & $4,47 \pm 0,56 b c$ & $4,93 \pm 0,35 b$ & $4,70 \pm 0,50$ \\
\hline Superjovem & $5,95 \pm 0,38 \mathrm{a}$ & $4,26 \pm 0,62 \mathrm{c}$ & $5,11 \pm 1,01$ \\
\hline Média & $5,21 \pm 0,90$ & $4,60 \pm 0,59$ & \\
\hline \multicolumn{4}{|c|}{ Pescoço, \% } \\
\hline Jovem & $6,85 \pm 0,38$ & $7,99 \pm 1,73$ & $7,42 \pm 1,33$ \\
\hline Superjovem & $5,68 \pm 0,14$ & $8,24 \pm 1,30$ & $6,96 \pm 1,60$ \\
\hline Média & $6,26 \pm, 067 \mathrm{~B}$ & $8,11 \pm 1,45 \mathrm{~A}$ & \\
\hline \multicolumn{4}{|c|}{ Acém, \% } \\
\hline Jovem & $4,54 \pm 0,53$ & $5,99 \pm 0,47$ & $5,26 \pm 0,90 \mathrm{~A}$ \\
\hline Superjovem & $2,98 \pm 0,23$ & $4,62 \pm 0,72$ & $3,80 \pm 1,00 \mathrm{~B}$ \\
\hline Média & $3,76 \pm 0,91 \mathrm{~B}$ & $5,31 \pm 0,92 \mathrm{~A}$ & \\
\hline \multicolumn{4}{|c|}{ Peito, \% } \\
\hline Jovem & $3,54 \pm 0,37 b$ & $3,18 \pm 0,31 b$ & $3,36 \pm 0,37$ \\
\hline Superjovem & $3,78 \pm 0,45 a b$ & $4,39 \pm 0,67 \mathrm{a}$ & $4,09 \pm 0,63$ \\
\hline Média & $3,66 \pm 0,41$ & $3,79 \pm 0,80$ & \\
\hline
\end{tabular}

A, B: letras diferentes na coluna ou na linha diferem $(\mathrm{P}<0,05)$ na mesma característica, pelo teste $\mathrm{t}$.

$\mathrm{a}, \mathrm{b}, \mathrm{c}$ : médias seguidas por letras minúsculas diferentes, para mesma característica, diferem $(\mathrm{P}<0,05)$ pelo teste $\mathrm{t}$.

Nos demais cortes do dianteiro, pescoço e acém, verifica-se superioridade dos animais não castrados em relação aos castrados de 29,5 e $41 \%$, respectivamente. Além disso, para o corte acém, observa-se superioridade em 38\% em favor dos animais jovens.

Na Tab. 6, são apresentados os cortes desossados do corte serrote. Apenas o contrafilé apresentou interação significativa entre categoria e condição sexual, sendo observado maior peso relativo em favor dos animais jovens castrados em relação aos demais. Para o corte filé-mignon, observa-se maior proporção em favor dos animais superjovens, ao passo que os animais jovens apresentaram maiores pesos relativos para a alcatra e o músculo do serrote. Para os demais cortes, não foram observados efeitos da condição sexual ou da categoria sobre a proporção deles. 
Tabela 6. Rendimento dos cortes desossados do serrote de bovinos terminados em confinamento, de acordo com a categoria e a condição sexual

\begin{tabular}{|c|c|c|c|}
\hline \multicolumn{4}{|c|}{----- Condição sexual ----- } \\
\hline Categoria & Castrado & Não castrado & Média \\
\hline \multicolumn{4}{|c|}{ Filé-mignon, \% } \\
\hline Jovem & $1,27 \pm 0,09$ & $1,49 \pm 0,14$ & $1,38 \pm 0,16 \mathrm{~B}$ \\
\hline Superjovem & $1,67 \pm 0,30$ & $1,73 \pm 0,28$ & $1,70 \pm 0,28 \mathrm{~A}$ \\
\hline Média & $1,47 \pm 0,30$ & $1,61 \pm 0,25$ & \\
\hline \multicolumn{4}{|c|}{ Picanha, \% } \\
\hline Jovem & $1,50 \pm 0,25$ & $1,19 \pm 0,17$ & $1,34 \pm 0,26$ \\
\hline Superjovem & $1,35 \pm 0,34$ & $1,27 \pm 0,22$ & $1,30 \pm 0,27$ \\
\hline Média & $1,42 \pm 0,30$ & $1,23 \pm 0,19$ & \\
\hline \multicolumn{4}{|c|}{ Patinho, $\%$} \\
\hline Jovem & $4,81 \pm 0,20$ & $4,24 \pm 0,73$ & $4,53 \pm 0,59$ \\
\hline Superjovem & $5,34 \pm 1,58$ & $4,27 \pm 0,39$ & $4,80 \pm 1,22$ \\
\hline Média & $5,07 \pm 1,10$ & $4,26 \pm 0,55$ & \\
\hline \multicolumn{4}{|c|}{ Lagarto, $\%$} \\
\hline Jovem & $2,05 \pm 0,19$ & $1,95 \pm 0,22$ & $2,00 \pm 0,20$ \\
\hline Superjovem & $1,90 \pm 0,36$ & $1,86 \pm 0,16$ & $1,88 \pm 0,26$ \\
\hline Média & $1,98 \pm 0,28$ & $1,90 \pm 0,18$ & \\
\hline \multicolumn{4}{|c|}{ Coxão mole, \% } \\
\hline Jovem & $6,16 \pm 0,38$ & $6,15 \pm 0,30$ & $6,15 \pm 0,32$ \\
\hline Superjovem & $6,16 \pm 0,31$ & $6,23 \pm 0,38$ & $6,19 \pm 0,33$ \\
\hline Média & $6,16 \pm 0,33$ & $6,19 \pm 0,33$ & \\
\hline \multicolumn{4}{|c|}{ Coxão duro, \% } \\
\hline Jovem & $3,98 \pm 0,50$ & $3,63 \pm 0,39$ & $3,81 \pm 0,46$ \\
\hline Superjovem & $3,58 \pm 0,56$ & $3,88 \pm 0,19$ & $3,73 \pm 0,43$ \\
\hline Média & $3,78 \pm 0,54$ & $3,75 \pm 0,32$ & \\
\hline \multicolumn{4}{|c|}{ Maminha, \% } \\
\hline Jovem & $0,54 \pm 0,19$ & $0,48 \pm 0,12$ & $0,51 \pm 0,15$ \\
\hline Superjovem & $0,67 \pm 0,13$ & $0,50 \pm 0,12$ & $0,59 \pm 0,15$ \\
\hline Média & $0,60 \pm 0,17$ & $0,49 \pm 0,12$ & \\
\hline \multicolumn{4}{|c|}{ Alcatra, \% } \\
\hline Jovem & $4,98 \pm 0,76$ & $4,63 \pm 0,69$ & $4,80 \pm 0,71 \mathrm{~A}$ \\
\hline Superjovem & $4,13 \pm 0,48$ & $4,29 \pm 0,43$ & $4,21 \pm 0,44 \mathrm{~B}$ \\
\hline Média & $4,55 \pm 0,75$ & $4,46 \pm 0,57$ & \\
\hline \multicolumn{4}{|c|}{ Contrafilé, \% } \\
\hline Jovem & $7,88 \pm 0,73 \mathrm{a}$ & $5,52 \pm 0,39 \mathrm{c}$ & $6,70 \pm 1,36$ \\
\hline Superjovem & $6,33 \pm 0,40 b$ & $6,38 \pm 0,26 b$ & $6,36 \pm 0,32$ \\
\hline Média & $7,11 \pm 0,98$ & $5,95 \pm 0,55$ & \\
\hline \multicolumn{4}{|c|}{ Músculo, \% } \\
\hline Jovem & $4,99 \pm 0,55$ & $4,81 \pm 0,86$ & $4,90 \pm 0,69 \mathrm{~A}$ \\
\hline Superjovem & $3,72 \pm 0,66$ & $4,11 \pm 0,59$ & $3,92 \pm 0,62 \mathrm{~B}$ \\
\hline Média & $4,35 \pm 0,88$ & $4,46 \pm 0,79$ & \\
\hline
\end{tabular}

A, B: letras diferentes na coluna ou na linha diferem $(\mathrm{P}<0,05)$ na mesma característica, pelo teste $\mathrm{t}$.

$\mathrm{a}, \mathrm{b}, \mathrm{c}$ : médias seguidas por letras minúsculas diferentes, para mesma característica, diferem $(\mathrm{P}<0,05)$ pelo teste $t$.

\section{CONCLUSÃO}

Novilhos jovens apresentaram maior ganho de peso médio diário, bem como novilhos jovens não castrados apresentaram maior peso final.
Animais não castrados apresentaram maiores pesos de meia carcaça fria, percentual de dianteiro e porção comestível do dianteiro em relação aos castrados. 


\section{REFERÊNCIAS}

ANUÁRIO BRASILEIRO DA PECUÁRIA. Santa Cruz do Sul: Gazeta, 2015. 68p.

COUTINHO FILHO, J.L.V.; PERES, R.M.; JUSTO, C.L. Produção de carne de bovinos contemporâneos, machos e fêmeas, terminados em confinamento. Rev. Bras. Zootec., v.35, p.2043-2049, 2006.

FERNANDES, A.R.M.; SAMPAIO, A.A.M.; HENRIQUE, W. et al. Avaliação econômica e desempenho de machos e fêmeas Canchim em confinamento alimentados com dietas à base de silagem de milho e concentrado ou cana-de-açúcar e concentrado contendo grãos de girassol. Rev. Bras. Zootec., v.36, p.855-864, 2007.

FOOD and agriculture organization of the united nations: statistics division. 2015. Available in: http://faostat3.fao.org/faostat-gateway/go/to/home/E. Accessed in: 23 July 2015.

FREITAS, A.K.; RESTLE, J.; PACHECO,P.S. et al. Características de carcaças de bovinos nelore inteiros vs castrados em duas idades, terminados em confinamento. Rev. Bras. Zootec., v.37, p.1055-1062, 2008.

GOTTSCHALL, C.S.; CANELLAS, L.C.; MARQUES, P.M.; BITTENCOURT, H.R. Relações entre idade, peso, ganho médio diário e tempo médio de permanência de novilhos de corte confinados para abate aos 15 ou 27 meses de idade. Semina, v.30, p.717-726, 2009 .

HERSOM, M.J.; HORN, G.W.; KREHBIEL C.R.; PHILLIPS, W.A. Effect of live weight gain of steers during winter grazing: I. Feedlot performance, carcass characteristics, and body composition of beef steers. $J$. Anim. Sci., v.82, p.262-272, 2004.

MARCONDES, M.I.; VALADARES FILHO, S.C.; PAULINO, P.V.R. et al. Consumo e desempenho de animais alimentados individualmente ou em grupo e características de carcaça de animais nelore de três classes sexuais. Rev. Bras. Zootec., v.37, p.2243-2250, 2008.

MISSIO, R.L.; BRONDANI, I.L.; FREITAS, L.S. et al. Desempenho e avaliação econômica da terminação de tourinhos em confinamento alimentados com diferentes níveis de concentrado na dieta. Rev. Bras. Zootec., v.38, p.1309-1316, 2009.

MOLETTA, J.L.; TORRECILHAS, J.A.; ORNAGHI, M.G. et al. Feedlot performance of bulls and steers fed on three levels of concentrate in the diets. Acta Sci. Anim. Sci., v.36, p.323-328, 2014.
PACHECO, P.S.; RESTLE, J.; SILVA, J.H.S. et al. Desempenho de novilhos jovens e superjovens de diferentes grupos genéticos terminados em confinamento. Rev. Bras. Zootec., v.34, p.963-975, $2005 \mathrm{a}$.

PACHECO, P.S.; SILVA, J.H.S.; RESTLE, J. et al. Características quantitativas da carcaça de novilhos jovens e superjovens de diferentes grupos genéticos. Rev. Bras. Zootec., v.34, p.1666-1677, 2005b.

PACHECO, R.F.; CATTELAM, J.; DONICHT, P.A.M.M. et al. Características da carcaça e dos principais cortes comerciais de bovinos superprecoces, terminados em confinamento. Magistra, v.25, p.138$147,2013$.

PINTO, A.; PASSETTI, R.A.C.; GUERRERO, A. et al. Concentrate levels of crossbred bulls slaughtered at 16 or 22 months: performance and carcass characteristics. Acta Sci. Anim. Sci., v.37, p.149-157, 2015.

PRADO, I.N.; EIRAS, C.E.; FUGITA, C.A. et al. Animal performance and carcass characteristics of bulls (1/2 Purunã vs $1 / 2$ Canchim) slaughtered at 16 and 22 months old, and three different weights. Asian Australas. J. Anim. Sci., v.28, p.612-619, 2015.

RESTLE, J.; ALVES FILHO, D.C.; FATURI, C. et al. Desempenho na fase de crescimento de machos bovinos inteiros ou castrados de diferentes grupos genéticos. Rev. Bras. Zootec., v.29, p.1036-1043, 2000.

RUBIANO, G.A.G.; ARRIGONI, M.B.; MARTINS, C.L. et al. Desempenho, características de carcaça e qualidade da carne de bovinos superprecoces das raças Canchim, Nelore e seus mestiços. Rev. Bras. Zootec., v.38, p.2490-2498, 2009.

SEIDEMAN, S.C.; CROSS, H.R.; OLTJEN, R.R.; SCHANBACHER, B.D. Utilization of the intact male for red meat production: a review. J. Anim. Sci., v.55, p.826-840. 1982.

SILVA, N.R.; FERREIRA, A.C.H.; FATURI, C. et al. Desempenho em confinamento de bovinos de corte, castrados ou não, alimentados com teores crescentes de farelo do mesocarpo de babaçu. Cienc. Rural, v.42, p.1882-1887, 2012.

VÉRAS, R.M.L.; VALADARES FILHO, S.C.; AZEVÊDO, J.A.G. et al. Níveis de concentrado na dieta de bovinos Nelore de três condições sexuais: consumo, digestibilidades total e parcial, produção microbiana e parâmetros ruminais. Rev. Bras. Zootec., v.37, p.951-960, 2008.

VITTORI, A.; GESUALDI JÚNIOR, A.; QUEIROZ, A.C. et al. Desempenho produtivo de bovinos de diferentes grupos raciais, castrados e não-castrados, em fase de terminação. Arq. Bras. Med. Vet. Zootec., v.59, p.1263-1269, 2007. 